\title{
Keeping Lily Safe: An Autoethnographic Exploration of Human-Animal Attachment during Adversity
}

\author{
Catherine Lee ${ }^{(1)}$ \\ Faculty of Health, Education, Medicine and Social Care, Anglia Ruskin University, Chelmsford, Essex CM1 1SQ, \\ UK; catherine.lee@anglia.ac.uk
}

Received: 20 May 2019; Accepted: 17 July 2019; Published: 18 July 2019

\begin{abstract}
This article is an autoethnographic examination of my experiences as a pet owner during a particularly challenging time in my life. Beginning with a summary of a critical incident, it shows the way in which fears for the safety of my pet cat, Lily, and my relationship with her impacted my health, wellbeing and identity. Depicting self-knowledge as partial, local and culturally located, I deconstruct the relationship I had with Lily in relation to the particular set of circumstances in which it was situated. I was seen by my doctor and prescribed a course of cognitive behaviour therapy (CBT) during this period, and so, my account draws on my medical records, CBT notes and my CBT thought diary in an attempt to understand how and why my anxiety was manifested in my concern for Lily. The article calls for cognitive behaviour therapists to carefully evaluate external stressors before fears are dismissed irrational and reformulated as alternative thoughts. This article also demonstrates that familiesare diverse, and there are many ways of 'doing family'. For many heterosexual and same-sex couples, pets give stability to a partnership and elevate it to family status, if only within the privacy of the home. Human-animal attachments can be comparable to human-human attachments, and where attachments to pets are as strong as those toward humans, fear of harm can be devastating.
\end{abstract}

Keywords: family; CBT; autoethnography; pets; homophobia; LGBT

\section{Introduction}

This article is an autoethnographic examination of my experiences during a particularly challenging time in my life. Beginning with a summary of a critical incident, my narrative shows the way in which fears for the safety of Lily, my companion animal, and my relationship with her impacted my health, well-being and identity. Grounded in an interpretivist philosophy, my autoethnographic account utilises writing about the self as a method of inquiry. Depicting self-knowledge as partial, local and culturally located, I critically examine the human-animal relationship I had with Lily in relation to the particular set of circumstances in which it was situated. Of primary importance during this period was the imposition of medical definitions of the situation, as I was seen by my doctor and prescribed a course of cognitive behaviour therapy (CBT). Consequently, my autoethnographic account draws on my medical records, CBT notes and my CBT thought diary in an attempt to understand how and why my anxiety was manifested in my concern for Lily. Additionally, since there is a dearth of research on human-animal relationships during adversity, this article answers in part the call of Zilcha-Mano et al. (2012) and others for a scholarly examination of people's relationships with companion animals during 'difficult life situations' (p. 9). My account, similar to the redemption narratives of homeless people elaborated upon in Irvine's (2013) research, shows the ways in which people construct and revise their sense of self by telling stories that describe their relationships with animal companions. 
This article begins with a brief description of the critical incident followed by a discussion of the autoethnographic methodology. Then, drawing on pertinent literature, I analyse how my relationship with, and fears for, Lily manifested themselves during this challenging period.

It is beyond the scope of this paper to share the entire critical incident upon which this article is based. What follows is a synopsis of the salient events. Even though this story is primarily about me, at its core is the behaviour of others, as well as my relationships with them. Tolich (2010) casts the word 'auto' when applied to autoethnography as a "misnomer", describing the self as "porous", inevitably "leaking" onto others, (p. 1608). The others mentioned in the narrative are 'characters', only partially depicted to help tell this story. Pseudonyms (Jo, Mr. Freeman and even Lily) or role titles (e.g., therapist, headteacher) are used throughout to protect the identities of all the others to whom I refer.

During the critical incident, I lived with my civil partner, Jo, and our cat, Lily, in rural southeast England. We had a house surrounded on three sides by fields belonging to the local wildlife trust. In June 2009, the neighbouring farmhouse-the only other property for half a mile-was sold to the Freemans (a pseudonym), a family of seven. They moved in and enrolled three of their children at the school at which I was assistant headteacher. The Freemans had a garden of six acres, but placed a trampoline immediately abutting our property line, no more than 15 feet from our kitchen and living room windows. My partner and I were upset at this intrusion into our privacy and decided to introduce ourselves and welcome the Freemans to the village, hoping in the process for an opportunity to mention the trampoline issue. Mr. Freeman proudly showed us around the grounds of his new property, and Jo sensitively broached the subject of the trampoline, explaining that I was a teacher at the school his children attended and that it was important to me that professional and personal boundaries did not become blurred. Mr. Freeman agreed and happily moved the trampoline. We thanked him for appreciating our position and rounded off the encounter in a cordial and neighbourly manner, leaving with an invitation to their housewarming party. Later that evening, banging on the front door interrupted our conversation. Mr. Freeman was pacing on and off the doorstep shouting that he would not be told what to do by a pair of lesbians and that he was going to make our lives a 'living misery'. He added that he owned a public relationscompany and would expose us online, though for what he did not say. He also told me that he would report me to my headteacher but, again, did not state for what. We stood paralysed as Mr. Freeman spat out more and more frustrated threats.

The following weeks were unhappy and uncomfortable. Though no further words were exchanged with the Freemans, Mr. Freeman pursued and provoked us at every opportunity. He called us 'dykes', and 'lezzers'; he urinated in our garden, appeared at our windows late at night and tried to run us off the narrow country lanes in his enormous black SUV. We became an obsession to him. He could not rest if we were outside, and he shouted or howled and laughed loudly and inexplicably at us. He threw things over the fence to startle us; on one occasion it was a bucket and, on another, the Freeman family bag of clothes pegs.

Because our property and Mr. Freeman's were isolated from the rest of the village, Jo and I were too afraid to contact the police. To do so would provoke Mr. Freeman further, and it was unlikely that the police could protect Jo, Lily or me in such a remote location. Instead, we put our home of 15 years on the market and made plans to relocate to another home well away from Mr. Freeman.

In October 2009, whilst our house was on the market, my headteacher asked to see me in his office. Mr. Freeman had come to the school to tell my headteacher that I was a lesbian and express concern that I was working with children. My headteacher said, "this man has a real problem with you, and I suggest you sell your house as quickly as possible". Although my headteacher stressed that he was not concerned by Mr. Freeman's complaint, he made it clear that it was a personal matter and asked that I keep him out of it, as getting along with parents was key to his role at a middle-class school such as ours. 


\section{Autoethnography}

Autoethnography is grounded in a postmodern, interpretivist philosophy and transcends the debate about reflexivity and voice in social research. It emphasises the interpretation of the researcher's behaviours, thoughts and experiences in relation to the culture and relationships in which they are situated (Chang 2008). Autoethnography permits access to "covert, elusive, and/or personal experiences like cognitive processes, emotions, motives, concealed actions, omitted actions, and socially restricted activities" (Rodriguez and Ryave 2001, p. 3). The unorthodox position of the autoethnographic researcher makes them well placed to study sensitive topics, giving a voice to those previously silenced or marginalized. Autoethnography has the potential to further academic understanding of the lives of many different people and give legitimacy and a community to those previously isolated and excluded by the dominant discourse of society.

Anderson and Glass-Coffin (2013) suggest that the praxis of autoethnography must remain fluid, and the use of data, documents and artefacts may be deployed in the best interests of supporting the narrative and facilitating visibility of the self. Chang too argues that multiple sources of data provide bases for triangulation that have the potential to help enhance content accuracy and validity of autoethnographic writing. Clandinin and Connelly (2000) also advocate the use of external data sources in autoethnography, stating that they "help fill in the richness, nuance, and complexity of the landscape, returning the reflecting researcher to a richer, more complex, and puzzling landscape than memory alone is likely to construct" (p. 83).

It should be noted that the critical incident occurred seven years before I made the decision to write publicly about it. The starting point for my narrative was to assemble the abundance of external data that had been created between 2009 and 2010, at the time of the critical incident. During this period, I sought medical help from my general practitioner (GP), who referred me to a cognitive behaviour therapist for stress and anxiety. I sought and was granted permission from my GP and CBT therapist to use the notes they made for the purpose of this research, and these documents were sent to me. By utilizing third-party data, I was able to see myself as the GP and the CBT therapist saw me at the time, but equally, I was able to provide a commentary to that evidence, providing footnotes of sorts to the data sources. This data also helps to highlight these professionals' lack of understanding of the way in which I, as a childless lesbian in a same-sex relationship, framed my identity and my notion of family in relation to Lily.

\section{Lily}

Franklin (2015) notes that cats have lived alongside humans for more than 5000 years, aligning their modes of communication and social behaviour with ours. Women are more likely than men to ascribe family membership to a dog or cat, and some report feeling closer to their animals than to other human family members (Charles 2014). Historically, cats became associated with deviant femininity through their association with witches and spinsters (Radulovic 2017). The cat/lesbian connection is a well-documented trope in popular Western culture, representing the rejection of the roles of wife and mother and the queering of the heterosexual, patriarchal family. Radulovic (2017) states that for many lesbians, loving cats is an intrinsic part of queer, lesbian identity. Both lesbians and cats are, according to Radulovic, similar in their rejection of typical modes of social affection. Just as the cat demands attention on her own terms and is considered less people-oriented than the dog, so may lesbians reject traditional female roles. Caring for cats enables lesbians to reclaim elements of caretaking in female identity without being subjected to patriarchal pressures of motherhood Conversely, the same lesbian/cat trope commonly represented as 'the mad cat lady'has a heteronormative and anti-lesbian interpretation in which lesbians who reject parenting are perceived as being odd, deficient or strange in some way (Clarke et al. 2018).

I had 'rescued' Lily as a semi-feral farm kitten in 1997, bringing her home as a surprise present for Jo. I longed to be a parent and especially for Jo and me to be a family. Zilcha-Mano et al. (2012) describe the human-animal relationship as involving mutual interdependence, with companion animals serving 
as a safe haven and secure base for the people with whom they live. The human-human bond required for psychological and physical health has been expanded to the human-animal bond and can be key in defining one's identity as a nurturing person.

In 1997, in rural England, same-sex parenthood seemed entirely implausible to Jo and me. Our conservative rural community was not ready for a same-sex couple, let alone a same-sex couple with a child, and our own families acknowledged us only as housemates rather than partners. My role as a teacher also necessitated the careful management of my personal and professional identities. Since 1988, the sanctioning of lesbian and gay families in English schools as 'pretend' had been law. Section 28 of the Local Government Act (1988-2003) prevented "the teaching in any maintained school of the acceptability of homosexuality as a pretended family relationship" (Local Government Act 1988). As a lesbian teacher during that period I, like others, believed that if my sexual identity became common knowledge, I would lose my job. My relationship with Jo was authentic only within the safe haven of our home, and I recognized that parenting would entail us facing the outside world as a couple. At the time, this felt unthinkable, and so, instead, within the safe haven of our home, Lily, for me at least, became the child I perceived society would not let me have.

Lily was twelve years old when the Freemans arrived. A major manifestation of my anxiety during this critical incident surrounded concerns about Lily's safety. As soon as the Freeman family arrived at the farm, I became aware of this emerging anxiety. Even before the critical incident, I felt uneasy about her safety as I observed the family and their animals arrive, unfurl themselves and, with little regard for the boundary separating their garden from ours, begin to explore boisterously their new environment.

Trigg et al. (2016) observe that levels of companion animal and human attachment influence the way in which humans view risk, appraise threat, and respond to environmental hazards. After the initial doorstep threats from Mr. Freeman, my levels of worry for the safety of Lily, Jo and me quickly became unmanageable. I struggled to imagine or articulate the danger that I thought that Jo and I were in, but I could imagine the harm Mr. Freeman might cause Lily. I had a recurring and intrusive thought that if Lily wandered beyond our garden onto the farm, as she had done for her entire twelve years with us, Mr. Freeman might sweep her up by the scruff of her neck, slit her throat with the knife I imagined he carried and toss her back over the fence to land in our garden.

At school, the morning after the doorstep incident, I confided in the school counsellor, telling her all about the events of the previous evening. I described the anxiety I felt, being at school whilst Lily inevitably roamed the fields around Mr. Freeman's farm. The school counsellor booked an appointment at the GP for me. After the consultation, the GP recorded the following observations about me in his notes.

GP Notes 17 July 2009

E: Adjustment Reaction

S: Dispute with new neighbours last night. Feels threatened, fear of harm to her pet cat.

I was embarrassed that my medical records refer to a fear of harm to my 'pet cat'. The statement appears frivolous amongst the courier script pages of serious codes and symbols denoting blood test results and prescription medicine. The discourse with Mr. Freeman was described only as a dispute with a neighbour, but this paid insufficient regard to his aggression and to the fear we felt at the time. When Mr. Freeman swaggered onto our doorstep, his need to hurt us effervesced from him. Lily's innocent and aimless meanderings onto the farm seemed to provide him with the easiest and cruellest of opportunities to achieve his aim. Now, ten years later and able to reflect on the incident from a position of good health, I recognise that my embarrassment is misplaced. Walsh (2009) notes that clinicians seeking to understand family functioning and to identify resources for healing and resilience usually ask about important persons in kin and social networks but rarely consider animal companions. My GP did not consider that as a childless lesbian, my attachment to Lily may have been greater than that of a typical family 'pet'. 
Drawing on Mikulincer and Shaver (2007), Trigg et al. (2016) state that human-animal attachments are fundamentally similar to human interpersonal relationships. They assert that for animals to be considered attachment figures, four criteria are required: (1) proximity maintenance-the company of the attachment figure is enjoyed and prolonged; (2) safe haven-they are sought out as a source of protection, support and comfort that relieves distress; (3) secure base-they represent a reliable presence that facilitates and permits risk-taking, tolerance of uncertainty and promotes environmental exploration; and (4) separation distress-a reaction prompted by distancing from or actual loss of the figure (p. 58). Applying the assertions of Trigg et. al. to my own set of circumstances, I feared the loss of Lily at the hands of Mr. Freeman. Lily symbolized for me the home and family, but the security and safe haven of home was compromised each time Lily went outside. Walsh (2009) asserts that families value their animal members most at times of crisis and loss, through disruptive transitions and in weathering prolonged adversity. Lily became the embodiment of my vulnerability as part of a same-sex couple, and as Mr. Freeman's behaviour towards us continued, I needed our family identity more than ever to counter the negativity and threat I faced when I ventured outside of our home.

An additional fear for Lily's safety emerged from a frequently repeated event. Mr. Freeman owned a tom cat and two aggressive dogs. His animals were daily and nightly visitors to our garden and regularly chased Lily back to our house and right up to the cat flap. As Mr. Freeman's cat grew bolder and more successful in his territorial dominance, he often did not curtail his pursuit at the cat flap and continued the chase into the house, up the stairs and into our bedroom. The commotion in the bedroom as Lily tried to fight off Mr. Freeman's cat always woke me with a start, and during the night, this event always seemed especially grave. After one incident, I recorded my concerns in the thought diary I was asked to keep by the CBT therapist:

Thought Diary: Thursday 1:40 a.m.

Lily has nowhere safe left to be. Why is he invading us in our home? Their cat is doing exactly what he [Mr. Freeman] is doing. Please, just leave us in peace and stop making our lives a misery.

Mr. Freeman's tom cat became the representation of Mr. Freeman. Each time the cat entered our house and chased Lily into our bedroom, it was as though Mr. Freeman himself had entered that most intimate and private area of our home. Though I recorded in the thought diary that Lily had nowhere safe left to be, it was perhaps Jo and me to whom I referred. It was impossible to find a single space in which Mr. Freeman was unable to reach us, and he, via his cat, had now penetrated the most intimate place in our home.

Privacy is often closely associated with safety (Elwood 2000). This is because when privacy is successfully achieved, it results in the creation of a place resistant to the influence of others. Comerford et al. (2004) describe the rural home as a site of crucial importance for lesbians and, for some, the only place in the countryside in which the lesbian relationship is acknowledged. Gorman-Murray (2006) similarly suggests that in 'homemaking', lesbian and gay couples seek to create a sanctuary or retreat in which to affirm the identities and relationships that are inhibited in everyday public spaces. It is my contention that for rural lesbian couples seeking to conceal their relationship, the home can feel central to the entire relationship. The home may feel as though it is the only place in which the relationship is real, and consequently, surveillance of the home can feel disproportionately threatening. Equally, when one feels under threat, the home can feel especially important as a site of safety or sanctuary. Mr. Freeman violated our home as a place of safety, but paradoxically, the less safe I felt at home, the more I was compelled to spend time there.

It became very uncomfortable for me to let Lily go outside. However, it was cruel and similarly distressing to keep this farm cat locked inside our cottage all day and all night. Shore et al. (2006), describe how increased attachment to companion animals is associated with greater likelihood of keeping them indoors, as the threatened loss of personally meaningful human-animal attachments can lead to anticipatory distress (Trigg et al. 2016, p. 63). 
As my anxiety and fear of Mr. Freeman grew, I kept Lily inside, feeling conflicted as she paced up and down miserably by the door, repeatedly nudging the cat-flap with her head and looking at me to provide a solution. Zilcha-Mano et al. (2012) state that a person's level of anxiety correlates with the degree to which he or she worries that an attachment figure will not be available in times of need. This leads to the adoption of "hyperactivating" attachment strategies-energetic, insistent attempts to obtain care and support as a means of regulating distress (p. 1). Not only did I fear that Lily would be harmed by Mr. Freeman, but I also depended on her presence in the home as a source of comfort as I became increasingly distressed.

As Lily had never been kept inside before, she became distressed when I would not let her go outside. I, therefore, let her out, but because I did so in full knowledge that she was in danger, I felt that I had an enhanced sense of responsibility for her fate. According to De Silva and Rachman (2004), people with anxiety have an exaggerated appraisal of risk and an overinflated sense of being personally responsible for avoiding and preventing harm and disaster. Twelve days after my initial referral to the GP, the doctor conducted a review of my progress:

GP Notes 29 July 2009

\section{E: Adjustment Reaction}

S: Anhedonia, obsessive checking, low mood, poor sleep ... self-loathing, poor concentration, anxiety and restlessness ++

The neighbour dispute and fear of harm to my 'pet cat' had made way for anhedonia, obsessive checking and self-loathing. The language presents a deviation from a social model in which I am distressed by aggression from a neighbour and am suffering from an adjustment reaction to an outside stimulus to a medical model in which it is my psychological state, not external circumstances, that is of concern. In simply anticipating through intrusive thoughts that Mr. Freeman might hurt us, it seemed that I had lost the ability to gain enjoyment from anything. Again, the notes taken by the GP imply that my reaction to the homophobic harassment by Mr. Freeman and my concern for Lily's safety was irrational. My symptoms represented my poor health rather than being understood by the GP as proportionate for someone who feels under threat at home and in the workplace and fearful that Lily, a family member, is going to come to physical harm.

Irvine (2013) notes the human perception of the innocence of animals. She states that animals do not judge those on the margins of society and stand as silent witnesses to our behaviour. The name calling caused a dramatic loss of my confidence, and I depended on Lily even more as I perceived her to be the only one not judging me. Putney (2014) suggests that lesbians who have faced societal intolerance often look to companion animals for validation. She states that the relationships between humans and companion animals help nurture an individual's sense of self that may not otherwise be possible. Animals promote self-efficacy and encourage the humans that live with them to accept their strengths and flaws. Companion animals provide a non-judgmental presence that can be internalized in ways that help shape how an individual defines and experiences themselves. The Freeman family had, if only by comparison, exposed us as an odd and anxious lesbian couple, unjustifiably intolerant of the intrusion of the Freeman children and their trampoline into our neat, ordered and peaceful lives. I hated that we were an unorthodox couple, playing at family with only a cat for a child. I consequently began to feel that we belonged on the side-lines and were not entitled to participate fully in real life.

What right did I have to try to control where a proper family might position the children's trampoline?

Roseneil and Budgeon (2004) state that "the idea of 'family' retains an almost unparalleled ability to move people, both emotionally and politically" (p. 135). According to Trussell and Shaw (2009), rurality and family life are synonymous with one another. Rural communities are widely considered to be a more suitable place to raise a family than a town or city. Trussell and Shaw argue that this is because rural communities are often perceived as close-knit, caring and surrounded by the simplicity and peacefulness of the natural environment. However, rural perceptions of the roles of animals differ 
compared with those of people living in towns and cities (Gorman 2017). A strong tradition of farming means that in rural communities, companion animals are more likely to be conceived of as labour and to live entirely outside the family home.

The human heterosexual family is privileged and protected in rural communities. Berlant and Warner (1998) argue that heteronormative societal belonging is constructed through the restriction of "a historical relation to futurity" (p. 318) and a discourse that privileges a "generational narrative and reproduction" (Berlant and Warner 1998). It is this focus on reproduction and future generations that gives the heterosexual family its privileged status. Oswald et al. (2005) observe that in heteronormative discourses, only heterosexual families are real. "Pseudo families" (p. 144) are their binary opposite. The privileging of the heterosexual Freeman family reminded me of the inauthentic nature of my partnership with Jo.

My perception of my relationship as 'pretend' was compounded by the lack of appropriate language to describe care-taking relationships beyond the heterosexual family. For example, heterosexual couples are often described as 'trying to start a family', compounding the notion that family can consist only of a heterosexual couple and their biological offspring. Clarke et al. (2018) describe being lesbian and childfree as a "double whammy", identifying that these two "forms of difference" make it "difficult to connect with (heterosexual) people in mundane situations" (p. 4148).

Whist heterosexual couples could marry, at the time, in England, those in same-sex relationships were instead afforded a civil partnership. Like many same-sex couples, Jo and I entered into a civil partnership. The failure to call the union of a same-sex couple "marriage" in England until 2015, further secured the dominance of heteronormativity by positioning civil partnerships as 'pseudo-marriage'. Kitzinger and Wilkinson (2004) state that "the re-branding of marriage as 'civil partnership' is useful to governments in enabling them to extend rights to, and control over, same-sex relationships, while reserving the privileged status of 'marriage' for heterosexuals only" (p. 127).

That a civil partnership offered (mostly) equal rights and protection is irrelevant. The civil partnership created a binary with marriage, in which the civil partnership was seen as inferior or inauthentic when compared with the real thing. As it applied only to same-sex couples, to declare a civil partnership necessitated outing oneself as lesbian or gay. Hudak and Giammattei (2010) call for a "decentering" (p. 55) of the family. Drawing on Butler's theory of gender performativity, they reject essentialist notions of the family and argue for family as a performative act in which fluid, ambiguous and diverse representations of family can prevail. Perlesz et al. (2006) argue that conceiving of family as a performative act creates possibilities for relating and parenting outside of the bounds of the heterosexual family. According to Hudak and Giammattei (2010), the performative act of family or "doing family" (p. 53) entails "intentionally committing to add elements of responsibility and caretaking to the bonds of love, which usually embody roles traditionally assigned to kinship networks" (p. 52). 'Doing family' transforms it from a static essentialist entity to a verb, encouraging new and diverserepresentations of caretaking and responsibility within loving relationships. When one can 'do family', it becomes possible for kinship- and family-making between humans and animals to exist, recognizing the everyday experiences of those humans who share their domestic space with animals (Blackstone 2014).

The critical incident happened only days before the start of the school summer holidays, and as the long holiday period commenced, I became isolated and disconnected from normal life. As the majority of the adult population, including my partner, continued to work through the summer, I engaged in long solitary days, mostly staying alone at the house to keep an eye on Lily (and Mr. Freeman). I had few internal anchors, and it was very easy to make a new reality. Irvine (2013) explains that animals enrich the debate about isolation and disaffiliation and asserts that pets provide a sense of self-worth at times when resources for establishing personal significance are scarce. Putney (2014) found that in her lesbian participants, caregiving for animals was meaningful as it afforded them the opportunity to attune to something beyond themselves. During those long days inside our home, the only role I performed was of companion to and carer for Lily, and although life felt fairly intolerable, I 
was driven to get up each day, because I knew that without me, Lily would not be safe. I regularly and obsessively checked Lily's whereabouts. Prior to the school holidays, my concern for what Mr. Freeman might do to Lily caused me to begin locking her inside the house during the day. I came home from school at lunchtime to let her out and then would lock her back in the house until I came home in the evening. I continued to lock her inside if I left the house during the holidays, but now, alone all day and with more time to think, I imagined that Mr. Freeman might set fire to the house while I was out. This intrusive thought was soon accompanied by fear of an accidental house fire caused by my negligence. To avert the risk of fire, I began checking that all electrical appliances were unplugged from the wall before I left the house. It took me longer and longer to leave the house, as I walked around, yanking out the plugs to the tumble dryer, the washing machine, the coffeemaker, the kettle and toaster. I also pulled out the plug to the television, the landline phone base unit, the lamps and mobile phone chargers. Although I tried to see and acknowledge that I had removed the plug, I returned to the appliance time and again. I stared at the plug, on the floor or in my hand, trying to capture the image. I told and showed myself over and over again that the plug was well away from its socket until I thought I could retain in my mind a certainty that I had, in fact, removed the plug and not just imagined that I had. The CBT therapist diagnosed me with obsessive compulsive disorder (OCD). She wrote:

\section{CBT Notes 14 September 2009}

Work with OCD model gently encouraging her to challenge idea that it is her actions that are keeping her cat safe. Also to examine rules and assumptions about life and to look at core beliefs with a view to developing flexibility.

When I did manage to leave the house, I imagined the smell of burning, and often, even miles from the cottage, if I could smell a garden bonfire or see smoke in the air, I would immediately curtail my trip and return home to reassure myself that Lily was safe and then begin the compulsive checking process all over again. This process is typical of the cycle of obsession and compulsion described by DeSilva and Rachman:

When an obsessive compulsive patient engages in his compulsion he needs to carry it out precisely as he feels it ought to be done. If the behavior is disrupted then the compulsive ritual is invalidated and needs to be restarted. For long and complicated rituals this can be extremely time-consuming and exhausting (2004:19).

After every trip, I travelled home, becoming ever more anxious as I neared the cottage. On a cloudy or misty day, the natural elements were mistaken for smoke plumes, and this resulted in a frantic dash back to the house. Only when I returned inside could I be absolutely sure that the house was not ablaze. Radomsky et al. (2010) explain that compulsive checking leads to an inflated sense of responsibility for misfortune via a thought-action fusion. Even though I perceived that it was Mr. Freeman who wanted to harm Lily, I soon felt that it would be my carelessness that would cause her death. I saw that the degree of my attentiveness as being directly related to Lily's safety.

As Mr. Freeman's homophobic shouting and trespassing into our garden became more commonplace and extreme, I worried how I was going to manage Lily's safety from my school workplace. However, I did not return to work that September. Before the start of the new term, I was rushed into hospital with abdominal pain. A scan revealed three large ovarian cysts that had lain dormant for some considerable time. Trigg et al. (2016) stresses that an important facet of human psychological reliance on companion animals concerns separation distress. It felt like good timing and good fortune that the subsequent operation resulted in a further eight weeks off work. However, more time to check on Lily and Mr. Freeman also resulted in more time at home alone.

One of the only times each week that I left the house was to attend CBT sessions at the village surgery. In late September, I was allocated a newly qualified female cognitive behaviour therapist. She introduced me in her notes in the following way: 
CBT Notes 14 September 2009

Very tearful and anxious. Catherine is in same sex relationship. She is a teacher that hates the job and feels she has sabotaged her career. She has created an environment around herself which allows her to be at home as much as possible. This fulfils a need she has to look after their cat. Developed OCD in relation to cat ... Wants to be normal and not have unhelpful and frightening thoughts.

I recall stressing my fear of Mr. Freeman to the new therapist, but she does not refer to him at all in her introductory notes. Consequently, my concern for Lily appears devoid of context. Mr. Freeman is conspicuously absent from the list of stressors that have contributed to my problems. He is replaced by references to my same-sex relationship, my relationship with my home and the perception that I hated my teaching job and had 'sabotaged' my career. These aspects were indeed central facets of my distress, but only because Mr. Freeman had, through his homophobic behaviour, exposed and linked them together by way of a threat. Beck and Beck (2011) suggest that the cognitive behavioural therapist should identify the "cognitive, affective, and behavioral mechanisms (adaptive and maladaptive)" (p. 30) developed by the patient to cope with "dysfunctional beliefs" (Beck and Beck 2011, p.30). CBT has a good track record of dealing with obsessive compulsive disorder but is not typically deployed to deal with relationship issues. Perhaps, the CBT therapists honed in on the specifics of my OCD because of the unsuitability of this sort of therapy to address the cause of the OCD-my fear of Mr. Freeman.

The work with the cognitive behavioural therapist focused on challenging my belief that we were unsafe.

The therapist reported how the thought diary led me to recognise the extent to which my fears for Lily were impacting me adversely. he entered the following in her notes:

\section{CBT Notes 25 September 2009}

Kept thought diary which caused her to confront full impact of problem which had negative effect on her depression. Thoughts were that it is a scary world out there and it is important to feel safe all the time.

The therapist did not note why I was fearful. Instead, she attributed my fears to a general belief that "it is a scary world out there".

As instructed by the therapist, I wrote in my thought diary as part of an attempt to 'sit' with the uncomfortable feelings until they passed. Salkovskis et al. (2003) identify that compulsive behaviours neutralise intrusive thoughts. However, they also show that anxiety declines to comparable levels without neutralising if the patient can resist the compulsive behaviour. I struggled to sit with the anxiety as instructed and searched for certainty of Lily's safety. My compulsive checking gave me an enhanced sense of responsibility for her fate. It seemed however hard I tried, my mind constantly sought to show me every conceivable danger. Not only did threats emanate from beyond the home, I soon could not be certain of her safety with me, inside our home, either.

Thought Diary Thursday 11:00 p.m.

Lily has come upstairs and is now sleeping in the blanket box I have left open. Instead of being relieved I can see her, I am terrified the lid will fall on her-even though it can't as I've propped it open. Why do I do this? Why do I see danger in absolutely everything?

As I recovered from my operation, I began to worry about leaving Lily and returning to school:

Thought Diary Thursday 11:52 a.m.

Next door's cat has just stuck his head through the cat flap. He saw me and beat a hasty retreat. Is this happening every day? Is it just good luck that I'm here? I can't even feel relaxed that Lily is safe inside, because it's clear she's not even safe when she's indoors. Is it not even safe to go to work now? 
This entry in the thought diary suggests something of the anxiety I felt about returning to school. I did not know at the time whether Mr. Freeman had been into school during my period of absence to carry out his threat of reporting me to my headteacher, and whilst I worried about leaving Lily at home alone, my question "Is it not even safe to go to work now?" perhaps pertained as much to my own fears about what I might encounter upon my return to school as it did to my fears about being away from Lily and being unable to keep her safe.

Though I returned to work on schedule, my need to neutralize obsessive thoughts by checking on Lily made it very difficult to be away from the house for the duration of the school day. However, Mr. Freeman's homophobic name calling, howling and appearances at our windows made being at home as intolerable as being at school. Paradoxically, I strived all day to be at home, seeking the sanctuary and safe haven our home no longer provided. Of course, this was also in part because being able to monitor the movements of Mr. Freeman was less stressful than being at school and imagining what he might be capable of.

At breaktime, after a particularly difficult weekend with Mr. Freeman, I recorded in my thought diary my fear for Lily's safety, even though she was locked inside the house.

Thought Diary-Monday 11:42 a.m.

I want to go home and check she's OK. I'm convinced he's going to hurt her. What if he hurts her?

Until Mr. Freeman met with my headteacher to express concern about my sexual identity, my problems had been a shameful secret, unravelled once a week in a tiny office set aside for CBT at the GP surgery in the village. There is a man next door who shouts things at us because we are gay. Nobody hears him because we live in the middle of nowhere. I worry that he might hurt us, and I am anxious that somehow something bad will happen to Lily, our cat. Each week, after 50 minutes, I skulked out of the office with my fears temporarily soothed. In order to conquer the Mr. Freeman problem, I just had to change my thinking.

I attended my scheduled appointment with the CBT therapist the day after Mr. Freeman visited the school. In her notes, she wrote:

\section{CBT Notes 2 December 2009}

Catherine came to session in a very distraught state and said neighbour had gone into the school where she works and seen the headmaster apparently making homophobic comments and accusations to him. The head told Catherine that he clearly had a problem with her. Catherine is very frightened and it has raised all the old fears about the cat's safety and her own. She is worried about what this man is capable of doing as he seems to hate her. She feels vindicated that all the thoughts she had about him were actually correct and that she is right to be concerned. Tried to reduce arousal by listening and by reminding her that his behaviour did not undermine the progress she has made with response prevention. Suggested she gets legal advice from Citizens Advice Bureau. Does not want to alert police as she is concerned that this would affect potential sale of house. Feels this development may have an impact on urgency of finding new house.

When the therapist mentioned that I should seek legal advice from the Citizen's Advice Bureau or contact the police, her real-world suggestions startled me, seeming at odds with the dialogue typical of our sessions. Discussions usually stayed within the confines of my irrational 'worry world'. Each week the therapist chipped away at my fears with questions and reasoning, and I, desperate to feel better and be a good patient, did everything I could to accept the conclusions to which I was led. Currently, we were working on the likelihood of Mr. Freeman, 'also a cat owner', hurting Lily if she wandered onto his land. The therapist's repeated and rephrased questions would temporarily wear me down until I was able to concede that it was unlikely that 'a man who had a pet cat would feel able to kill another cat'. This week, however, though I conceded this point, I remained especially sceptical. The 
therapist's proposal that I seek real-world help suggested to me that she might not be convinced either. A week later, after the next CBT session, the therapist wrote:

\section{CBT Notes 9 December 2009}

Used session to work on remembering that her learning does not have to be altered by this latest experience. Disentangling thoughts and unreasonable link she has made e.g., although her neighbour is behaving unreasonably to her, this does not mean that he would hurt the cat. Evidence suggests that he is fond of animals and has pets himself.

This entry by the therapist marks the point at which I realized that CBT was not a suitable intervention for my fear of Mr. Freeman. She wrote that my "learning does not have to be altered" by Mr. Freeman's visit to school and that I had made an "unreasonable link" to believe that he was capable of hurting Lily. I desperately wanted the CBT to work and liked the therapist, but I knew that my concern over Mr. Freeman was not completely unreasonable or irrational. The therapist's determination to disregard Mr. Freeman and plough on caused me to lack trust in her. I began to worry that she might not tell me that Lily was in danger even if privately she thought Lily could be. In April 2010, we completed the sale of our home and moved into rented accommodation some fifty miles from Mr. Freeman. The days immediately after the move were amongst the happiest I can recall. Lily survived the long car journey and actually seemed to like her new surroundings. She was inquisitive, brave and playful. Jo and I felt as though we were on holiday. The final entry by the cognitive behaviour therapist, a few weeks after the move, reflected the transformation in my health and well-being.

CBT Notes 6 May 2010

Catherine was transformed! She was feeling really good and happy, better than she remembered ever feeling. Moving house has been a very positive change for her and she feels that her world has opened up.

Manzo (2005) asserts that home is not one stationary location but the process of travelling itself. She argues that people move on, physically or psychologically, to find places that are more congruent with their sense of self. Separation from previous environments and a movement toward new surroundings mark a new stage in life and new identity constructions. As we began to cover the grubby magnolia walls with fresh paint, I realised that our new house was already more of a family home for Jo, Lily and me than our cottage had been at any time since the arrival of Mr. Freeman.

\section{Conclusions}

In 2009, it was my core belief that Mr. Freeman intended to hurt Lily. Now, some ten years later and in good health, this remains my belief. Kitzinger (1997) argues that cognitive behaviour therapists should carefully evaluate external stressors before fears are dismissed and reformulated through alternative modes of thinking. She warns psychologists that a subjective focus for therapy based entirely on fixing the thinking of the individual potentially diminishes the importance of addressing social inequalities. She states:

If [psychologists'] aim is to decrease 'stress' and to increase the 'ego strength' of the victim, do they risk forgetting that it is the perpetrator, not the victim, who is the real problem? What political choices are they making in focusing on the problems of the oppressed rather than on the problem of the oppressor? (p. 213)

My referral for CBT to fix the problem of Mr. Freeman illustrates the point made by Kitzinger. The subjective approach served to exacerbate my feelings of inadequacy, exclusion and detachment from my surroundings by positing my view of Mr. Freeman's behaviour as irrational. Crucially, the GP and CBT therapist did not understand Lily's role in my life and the bond between us. Implicit in the 
CBT was a criticism of me being unable to cope with a set of circumstances that I was encouraged to believe were benign. CBT also led me to internalise further negative messages about myself, by making me believe that my judgment and reasoning were flawed. I echo Kitzinger's point in the strongest of terms. Those offering subjective interventions in cases of stressful events (such as hate incidents) should look to the external stressors in addition to the resulting manifestations of distress. The patient/client should be supported to get real-world (objective) support, and the credibility of any threat should be thoroughly explored before being dismissed as an irrational fear and reformulated as an alternative thought.

It is also important to recognise that there are many ways of 'doing family' (Hudak and Giammattei 2010). Laurent-Simpson (2017) recommends that professionals recognize modern depictions of families to include human-human companionships of choice and, crucially, multi-species cohabitation. 'Doing family' transforms it from a static essentialist entity to a verb, encouraging new representations of caretaking and responsibility within relationships of choice. For many heterosexual and same-sex couples, companion animals elevate partnerships to family status. According to Charles (2014), we are witnessing the emergence of hybrid families or post-humanist households where humans are de-centred and the species barrier has no meaning. This challenges assumptions that it is only humans who can be construed as kin. Similarly, Laurent-Simpson (2017) states that human-animal relationships may point to a general change in identity meanings and calls for a specialized focus within identity theory on the influence of non-human animals on identity formation (p. 629). In common with Charles and Laurent-Simpson, in this article, I demonstrate that human-animal attachments are comparable with human-human attachments, and where attachments to companion animals are as strong as those toward humans, fear of harm, loss of safe haven and eventually grief over the death of an animal can be devastating and akin to losing a human family member.

A shift in the cultural definition of family is long overdue in the United Kingdom (UK). Same-sex marriage was introduced in 2015, and the notion that family-building is only possible through the birth of biological children to heterosexual couples is becoming outdated as families become more diverse. The human-animal bond can help LGBT adults develop ways of being and seeing themselves that "present a buffer against the chronic strain of living in a heterosexist culture" (Putney 2014, p. 75). Although the body of research into human and companion animal relationships and families has grown since this critical incident took place, medical and psychological services, especially in the UK, must do more to understand and better support families that include companion animals, particularly during periods of adversity.

Funding: This research received no external funding.

Conflicts of Interest: The author declares no conflict of interest.

\section{References}

Anderson, Leon, and Bonnie Glass-Coffin. 2013. I learn by going: Autoethnographic modes of inquiry. In Handbook of Autoethnography. Edited by Stacy Holman Jones, Tony E. Adams and Carolyn Ellis. Walnut Creek: Left Coast Press, pp. 57-83.

Beck, Judith S., and Aaron T. Beck. 2011. Cognitive Behavior Therapy: Basics and Beyond. New York: Guilford Publications.

Berlant, Lauren, and Michael Warner. 1998. Sex in public. Critical Inquiry 24: 547-66. [CrossRef]

Blackstone, Amy. 2014. Doing family without having kids. Sociology Compass 8: 52-62. [CrossRef]

Chang, Heewon. 2008. Autoethnography as Method. Walnut Creek: Left Coast Press.

Charles, Nickie. 2014. Animals just love you as you are': Experiencing kinship across the species barrier. Sociology 48: 715-30. [CrossRef]

Clandinin, D. Jean, and F. Michael Connelly. 2000. Experience and Story in Qualitative Research. San Francisco: Jossey-Bass. 
Clarke, Victoria, Nikki Hayfield, Sonja J. Ellis, and Gareth Terry. 2018. Lived Experiences of Childfree Lesbians in the United Kingdom: A Qualitative Exploration. Journal of Family Issues 39: 4133. [CrossRef]

Comerford, Susan A., M. Maxwell Henson-Stroud, Corbett Sionainn, and Elizabeth Wheeler. 2004. Crone songs: Voices of lesbian elders on aging in a rural environment. Affilia 19: 418-36. [CrossRef]

De Silva, Padmal, and Stanley Rachman. 2004. Obsessive-Compulsive Disorder: The Facts. New York: Oxford University Press.

Elwood, Sarah A. 2000. Lesbian living spaces: Multiple meanings of home. Journal of Lesbian Studies 4: 11-27. [CrossRef]

Franklin, Adrian. 2015. Miffy and me: Developing an auto-ethnographic approach to the study of companion animals and human loneliness. Animal Studies Journal 4: 78-115.

Gorman, Richard. 2017. Therapeutic landscapes and non-human animals: The roles and contested positions of animals within care farming assemblages. Social and Cultural Geography 18: 315-35. [CrossRef]

Gorman-Murray, Andrew. 2006. Gay and lesbian couples at home: Identity work in domestic space. Home Cultures 3: 145-67. [CrossRef]

Hudak, Jacqueline, and Shawn V. Giammattei. 2010. Doing family: Decentering heteronormativity in "marriage" and "family" therapy. In AFTA Monograph Series: Expanding our Social Justice Practices: Advances in Theory and Training. Edited by Jane Ariel, Pilar Hernandez-Wolf and Sarah Stearns. Washington: American Family Therapy Academy, Inc., pp. 49-58.

Irvine, Leslie. 2013. Animals as lifechangers and lifesavers: Pets in the redemption narratives of homeless people. Journal of Contemporary Ethnography 42: 3-30. [CrossRef]

Kitzinger, Celia. 1997. Lesbian and gay psychology: A critical analysis. In Critical Psychology: An Introduction. Edited by Dennis Fox and Isaac Prilleltensk. Thousand Oaks: Sage, pp. 202-16.

Kitzinger, Celia, and Sue Wilkinson. 2004. The re-branding of marriage: Why we got married instead of registering a civil partnership. Feminism and Psychology 14: 127-50. [CrossRef]

Laurent-Simpson, Andrea. 2017. Considering alternate sources of role identity: Childless parents and their animal "kids". Sociological Forum 32: 610-34.

Local Government Act. 1988. Section 28. Available online: http://www.legislation.gov.uk/ukpga/1988/9/contents (accessed on 12 May 2012).

Manzo, Lynne C. 2005. For better or worse: Exploring multiple dimensions of place meaning. Journal of Environmental Psychology 25: 67-86. [CrossRef]

Mikulincer, Mario, and Phillip R. Shaver. 2007. Attachment in Adulthood: Structure, Dynamics, and Change. New York: Guilford Press.

Oswald, Ramona Faith, Libby Balter Blume, and Stephen R. Marks. 2005. Decentering Heteronormativity: A Model for Family Studies. In Sourcebook of Family Theory and Research. Edited by Vern Bengston, Alan C. Acock, Katherine R. Allen, Peggye Dilworth-Anderson and David M. Klein. Thousand Oaks: Sage, pp. 143-65.

Perlesz, Amaryll, Rhonda Brown, Jo Lindsay, Ruth McNair, David De Vaus, and Marian Pitts. 2006. Family in transition: Parents, children and grandparents in lesbian families give meaning to 'doing family'. Journal of Family Therapy 28: 175-99. [CrossRef]

Putney, Jennifer M. 2014. Older lesbian adults' psychological well-being: The significance of pets. Journal of Gay and Lesbian Social Services 26: 1-17. [CrossRef]

Radomsky, Adam S., Roz Shafran, Anna E. Coughtrey, and Stanley Rachman. 2010. Cognitive-behavior therapy for compulsive checking in OCD. Cognitive and Behavioral Practice 17: 119-31. [CrossRef]

Radulovic, Breck. 2017. Cat Call: How Lesbians Queer Society Through Interactions with Cats. Available online: http://midwayreview.uchicago.edu/a/13/1/Radulovic.pdf (accessed on 14 May 2019).

Rodriguez, Noelie Maria, and Alan Lincoln Ryave. 2001. Systematic Self-Observation: A Method for Researching the Hidden and Elusive Features of Everyday Social Life. Thousand Oaks: Sage.

Roseneil, Sasha, and Shelley Budgeon. 2004. Cultures of intimacy and care beyond 'the family': Personal life and social change in the early 21st century. Current Sociology 52: 135-59. [CrossRef]

Salkovskis, Paul M., Susan Thorpe, Karina Wahl, Abigail L. Wroe, and Elizabeth Forrester. 2003. Neutralizing increases discomfort associated with obsessional thoughts: An experimental study with obsessional patients. Journal of Abnormal Psychology 112: 709-15. [CrossRef] 
Shore, Elsie R., Michelle L. Riley, and Deanna K. Douglas. 2006. Pet owner behaviors and attachment to yard versus house dogs. Anthrozoös 19: 325-34. [CrossRef]

Tolich, Martin. 2010. A critique of current practice: Ten foundational guidelines for autoethnographers. Qualitative Health Research 20: 1599-610. [CrossRef]

Trigg, Joshua, Kirrilly Thompson, Bradley Smith, and Pauleen Bennett. 2016. An Animal Just Like Me: The Importance of Preserving the Identities of Companion-Animal Owners in Disaster Contexts. Social and Personality Psychology Compass 10: 26-40. [CrossRef]

Trussell, Dawn E., and Susan M. Shaw. 2009. Changing family life in the rural context: Women's perspectives of family leisure on the farm. Leisure Sciences 31: 434-49. [CrossRef]

Walsh, Froma. 2009. Human-Animal bonds II: The role of pets in family systems and family therapy. Family Process 48: 481-99. [CrossRef] [PubMed]

Zilcha-Mano, Sigal, Mario Mikulincer, and Phillip R. Shaver. 2012. Pets as safe havens and secure bases: The moderating role of pet attachment orientations. Journal of Research in Personality 46: 571-80. [CrossRef]

(C) 2019 by the author. Licensee MDPI, Basel, Switzerland. This article is an open access article distributed under the terms and conditions of the Creative Commons Attribution (CC BY) license (http://creativecommons.org/licenses/by/4.0/). 